\title{
NUCLEAR CRISIS STABILITY IN SOUTH ASIA
}

\section{Sumit Ganguly and Kent L. Biringer}

Relations between India and Pakistan have been fraught with conflict since their emergence from the detritus of the British Indian Empire in 1947. In the British Indian Empire, there were two classes of states. One set of states, those of British India, was directly under the tutelage of the British Crown. The others, the so-called princely states, were nominally independent as long as they accepted the British as the paramount power in the subcontinent. Since their independence from England, India and Pakistan have had markedly divergent concepts of nation building and quickly became embroiled over a territorial dispute involving the former princely state of Jammu and Kashmir.

The origins of this conflictual relationship have been discussed at length elsewhere. ${ }^{1}$ Since 1947, India and Pakistan have fought four wars, in 1947-48, 1965, 1971, and 1999. The last conflict did not see a formal declaration of war but easily met the criteria for a full-scale war. Apart from these engagements, much strife and tension have characterized the Indo-Pakistani relationship. More to the point, bilateral and multilateral efforts to resolve

Sumit Ganguly is Professor in the Department of Asian Studies and the Department of Government, University of Texas, Austin. Kent L. Biringer is South Asia Program Manager, Cooperative Monitoring Center, Sandia National Laboratories, Albuquerque, New Mexico. This work was supported by the U.S. Department of Energy through the Cooperative Monitoring Center at Sandia National Laboratories. Sandia is a multiprogram laboratory operated by Sandia Corporation, a Lockheed Martin Company, for the U.S. Department of Energy under Contract DE-AC04-94AL85000. The views presented here are the authors' own and do not necessarily reflect those of the U.S. Department of Energy or the Sandia National Laboratories.

Asian Survey, 41:6, pp. 907-924. ISSN: 0004-4687

(C) 2001 by The Regents of the University of California. All rights reserved.

Send Requests for Permission to Reprint to: Rights and Permissions, University of California Press, Journals Division, 2000 Center St., Ste. 303, Berkeley, CA 94704-1223.

1. For an account of the origins and evolution of the Indo-Pakistani conflict, see Sumit Ganguly, Fearful Symmetry: Explaining the Indo-Pakistani Conflict (New York: Columbia University Press, 2001). 
outstanding issues have met with little success. ${ }^{2}$ The end of the Cold War, which helped reduce tensions in various troubled regions of the world, did little or nothing to unravel the South Asian conundrum. The Indo-Pakistani conflict, which had preceded the intrusion of Cold War concerns into the subcontinent, continued unabated.

Since May 1998, in the aftermath of the Indian and Pakistani nuclear tests, the strained relationship has been further exacerbated. Two events in particular have contributed to the dramatic deterioration in Indo-Pakistani relations. The first was Pakistan's attempt to breach the Line of Control (LOC) near Kargil in Jammu and Kashmir in April-June 1999; the second was the overthrow of the civilian Pakistani regime of Prime Minister Mian Nawaz Sharif that October. ${ }^{3}$ The breach of the LOC inflamed public opinion in India, especially in light of the attempt earlier the same year to reduce tensions through the inauguration of a bus service linking the border towns of Amritsar and Lahore. The military coup that month further eroded an already denuded relationship as India's decision-makers placed even less trust in a Pakistani military regime. Not surprisingly, India went on to increase its defense budget by $28 \%$ and a fiscally troubled Pakistan raised its defense spending by $11 \%$. These budgetary increases took place despite numerous U.S.-supported bilateral sanctions imposed on both countries in the aftermath of the nuclear tests of 1998. It is important to underscore that the impact of bilateral sanctions on India and Pakistan was quite disproportionate. Pakistan's weaker and more internationally integrated economy suffered far more than that of India. ${ }^{4}$

As the year 2000 drew to a close, both sides continued to accuse each other of fomenting discord. India accused Pakistan of abetting terrorism in Kashmir, while Pakistan maintained that it was merely providing moral and diplomatic support for Kashmiris seeking their "inalienable right of selfdetermination." Despite these problems, a series of positive unilateral actions did take place near the end of the year. These included an Indian cease-fire

2. For a discussion of various attempts to settle Indo-Pakistani differences, see Sumit Ganguly, "Discord and Collaboration in India-Pakistani Relations" in Interpreting World Politics: Essays for A. P. Rana, eds. Kanti Bajpai and H. C. Shukul (New Delhi: Sage Publications, 1995).

3. For a discussion of the October coup in Pakistan, see Sumit Ganguly, "Pakistan's Chronic Coups," Foreign Affairs (March/April 2000), pp. 2-7. The literature on the Kargil conflict is voluminous. For the Government of India's formal report, see the Kargil Review Committee Report, From Surprise to Reckoning (New Delhi: Sage Publications, 2000); for a critical account, see Praveen Swami, The Kargil War ((New Delhi: Leftoword, 2000).

4. For a discussion of Pakistan's economic situation two years after the sanctions, see Ahmed Rashid, "Short-Term Relief," Far Eastern Economic Review (FEER), October 19, 2000, p. 86. For an analysis of India's economic status, see Joanna Slater, "Oil and Water Shock," FEER, November 2, 2000, p. 70. 
in Kashmir and a Pakistani withdrawal of some forces along the LOC. ${ }^{5}$ While little or no formal strategic dialogue developed between the two sides, some actions such as advanced notice of missile launches have been continued. There are also a growing number of Track II efforts to engage strategic thinkers on issues of regional nuclear stability. Additionally, a number of U.S. based nongovernmental organizations and universities have sought to promote nuclear dialogue in the region. However, despite continuing negotiations with the U.S., especially between the U.S. and India, neither India nor Pakistan showed willingness to curb their nuclear weapons and ballistic missile programs.

\section{Crisis Stability and Nuclear Safety}

In this state of heightened tensions, lack of dialogue, and declared nuclear weapon status, concerns over the stability and safety of a nuclearized subcontinent abound. Possession of nuclear weapons carries with it the potential for severe consequences in the course of normal and abnormal situations. What constitutes crisis stability and nuclear safety and why is it of such significance in the Indo-Pakistani context?

Crisis stability is a measure of a country's incentive not to strike preemptively in a crisis. Simply stated, it involves avoiding escalating to the top rung of the nuclear ladder in order to beat the adversary. Crisis stability is considered high when the incentives to strike first are low. It is of considerable significance in the Indo-Pakistani context for two compelling reasons. First, the region has witnessed a number of wars and crises. At least two of these crises may have had a nuclear component. Second, the mutual incentives to strike first would be great when the two sides have limited and vulnerable nuclear forces. Consequently, both sides would have strong incentives to strike first to prevent preemption. At the time of this writing and for the foreseeable future, both sides will have limited and potentially vulnerable nuclear forces. In addition to the problem of ensuring crisis stability, other sources of nuclear instability stalk the region. A number of scenarios can be envisioned that could threaten stability.

Technical failures can compromise nuclear stability. Mechanical or electrical malfunctions could result in a nuclear accident. Such malfunctions may be the result of factors such as design flaws, material aging, or mishandling. Accidents and other situations in which weapons are exposed to severe environments (e.g., fire, flood, and earthquake) pose potential safety and security risks. Failures of command and control procedures could lead to the unin-

5. For a discussion of the thinning out of forces along the LOC, see Karthik Nagarajan and Teresita C. Schaffer, "Pakistan Update," South Asia Monitor, Number 33, May 1, 2001, South Asia Program, Center for Strategic and International Studies, Washington, D.C. 
tended launch of a nuclear-armed missile. A rogue launch of a nuclear weapon could precipitate a nuclear exchange. Security breaches could result in nuclear weapons falling into the hands of terrorist groups or subnational actors. In the absence of robust surveillance capabilities, either side could launch nuclear weapons on the basis of faulty intelligence warnings. Such warnings could, for instance, erroneously report missile attacks requiring a quick response. A weapon-release authorization could also occur at the time of a nuclear weapons detonation before determining whether such a detonation was the result of an attack or an accident involving one's own weapon. Finally, instability is possible when faced with ambiguous but disturbing evidence of a massive conventional attack and the need to decide rapidly on the preemptive use of nuclear weapons. This is especially the case when significant conventional military asymmetry exists in a hostile dyadic relationship. Accordingly, in the Indo-Pakistani case, a Pakistani decision-maker, faced with seeming evidence of a massive Indian conventional attack, may be tempted to threaten the first use of nuclear weapons.

It is easy to exaggerate the fears of the likelihood of nuclear war in South Asia. Despite their long history of conflict and turmoil, neither India nor Pakistan is ruled by revolutionary regimes intent on fundamentally transforming the global or even the regional order though the use of force. This point is hardly of trivial significance in this discussion of nuclear stability in the subcontinent. Even professedly revolutionary states, driven by profound ideological hatred, such as the Soviet Union and the People's Republic of China (PRC), stopped short of nuclear escalation during the Ussuri River clashes of 1969. ${ }^{6}$ That said, there might still be some cause for concern about nuclear stability in the region. The principal sources of such concern stem from certain structural dimensions of the subcontinent, including the oddities of political geography, the ongoing conflict over Kashmir, the particular features of strategic doctrines, and the lack of diplomatic dialogue. Each of these concerns deserves discussion.

Unlike in the U.S.-Soviet case and much like the Sino-Soviet one, India and Pakistan have little or no warning time once either side launches ballistic missiles. An inadvertent or even deliberate but unauthorized missile launch from one of the border areas of either India or Pakistan has the potential of striking major cities within a span of a few minutes. Such short flight times dramatically reduce the margins for error. In a crisis, and in the absence of various agreed-upon technical limitations on missile flight paths and testing routines, both sides would have every reason to assume the worst of the other. Under such crisis conditions, a false warning of an impending missile

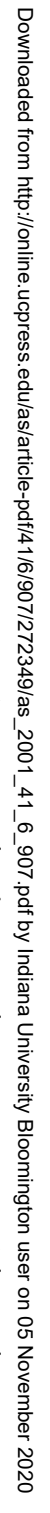

6. Harrison Salisbury, The Coming War Between Russia and China (New York: Norton, 1969). 
attack could lead one side or the other to strike first. Once launched, there would be little or no opportunity to alert the other side of an accidental or unauthorized launch.

Doctrinal issues can and are compounding the peculiarities of political geography on the subcontinent. Long before it tested nuclear weapons, Pakistan had moved toward an offensive military doctrine to cope with its lack of geographic depth. ${ }^{7}$ There is little reason to believe that it has eschewed such a conventional military posture despite its acquisition of some nuclear weapons capabilities. Is there any evidence that Pakistan has abandoned such a conventional military doctrine? There is little reason to think so. Even after its overt acquisition of nuclear weapons capabilities, Pakistan can ill-afford to concede territory to India in the event of a war. To this end, Pakistan has refused to accede to a no-first-use status. If Indian forces were to be pressing at its borders, Pakistan would reserve the right to threaten the adversary with nuclear weapons.

Though hard evidence to that end is difficult to come by, it is possible to infer that India, too, intends to carry the war into Pakistan's territory. ${ }^{8}$ To avoid the possibility of quick nuclear escalation, Indian defense planners argue that they would not make deep incursions into Pakistani territory but would escalate horizontally along a band of territory along the international border.9 Such a strategy may not necessarily assuage Pakistani anxieties. Pakistani military planners may still fear that such a broad-banded incursion may simply be the prelude to a deeper thrust along vulnerable salients.

The long history of conflict and turmoil reinforces the misgivings in both capitals about each other's intentions. Worse still, hyper-nationalist propaganda has the propensity of bolstering the direst assessments of each other's goals and likely behavior. ${ }^{10}$ Worse still, the ongoing conflict in Kashmir (which shows few, if any, signs of abating) makes elites in both Islamabad and New Delhi even more suspicious and wary of each other's moves. Pakistan continues to fecklessly supply the insurgents and India shows little imag-

7. Stephen P. Cohen, The Pakistan Army (Berkeley: University of California Press, 1984).

8. This can be best inferred from the configuration of the last major Indian military exercise, "Brasstacks." This exercise almost brought the two sides to war through a process of misperception and miscalculation. For an analysis of the Brasstacks crisis, see Kanti Bajpai et al., Brasstacks and Beyond: Perception and the Management of Crisis in South Asia (New Delhi: Manohar, 1995).

9. Based upon a personal interview with a senior Indian military officer, New Delhi, August 2000 .

10. For a discussion of the role of hyper-nationalist propaganda in heightening tensions, see Stephen Van Evera, The Causes of War: Power and the Roots of Conflict (Ithaca, N.Y.: Cornell University Press, 1999). 
ination in forthrightly addressing the genuine grievances of the Kashmiris. ${ }^{11}$ Continued massacres of civilians by the insurgents and periodic crackdowns by the security forces on the same population sustain the forces of hostility, instability, and violence in a seemingly never-ending spiral.

Finally, in the aftermath of the Kargil episode and the subsequent military coup in Pakistan, the diplomatic dialogue between India and Pakistan has come to a complete standstill. India insists that it cannot hold a dialogue with Pakistan until the latter ceases support for the insurgents in Kashmir. Parenthetically, India adds that it will not discuss its internal arrangements in Kashmir with Pakistan. Pakistan, by the same token, insists that it will be ready to start a dialogue with India only when the "core issue" of Kashmir is on the negotiating table. These two antithetical positions have contributed to a political deadlock.

\section{Key Concerns and Information Needs}

In a region faced with a variety of security concerns, it is important to understand how these concerns drive strategic decision making and contribute to increased or decreased stability. The role that information plays in this process is key. It will be necessary to strike a balance between providing transparency in which access to information adds to confidence and stability rather than undermining it, and maintaining opacity and ambiguity to ensure the deterrence sought by the regional players.

In assessing information needs, one must start with identification of the issues of greatest concern. The results will help define the sets of desired information. The categories of information needed may support a variety of purposes that include confronting issues of asymmetry in capabilities, assessing weapon system alert status, addressing safety concerns, and evaluating use control and implementation policies and effectiveness. Information on these concerns may be necessary for demonstrating treaty compliance when agreements exist or for building confidence and showing goodwill in periods prior to formal agreements. In addition to the transparency and opacity issues mentioned earlier, concerns over release of classified information may also be an impediment to obtaining desired information.

Because balance and parity are such important considerations in assessing strategic stability, information on quantities and capabilities of weapons systems will be a critical element in maintaining stability. Concerns over vulnerability and sufficiency of forces to mount a credible counterstrike can only be addressed by assessing force structure and capability.

11. Sumit Ganguly, The Crisis in Kashmir: Portents of War, Hopes of Peace (Cambridge: Cambridge University Press, 1999). 
Perhaps of greatest concern from the standpoint of stability is the issue of weapon alert status. Information that can provide insights into the alert status and readiness levels of adversarial forces can prevent unnecessary escalation of alert status that risks spiraling out of control toward nuclear employment. This information needs to be provided in ways that do not introduce vulnerabilities to the systems that one possesses. The goal is to have sufficient warning times to allow for resolution of any possible misinterpretations. Information that can discriminate between actual (e.g., missile attack) and perceived threat (e.g., missile test flight) will be a critical factor in maintaining nuclear stability.

While safety may be viewed as an issue only loosely connected with nuclear stability, the fact is that nuclear accidents could become the kindling for a full-scale nuclear conflagration. Nuclear accidents that result in a nuclear yield could be misinterpreted as attacks on nuclear sites. This may be especially true at times of conflict or conventional war. Other accidents that result in dispersal of radioactive material may pose environmental and humanrisk hazards across international boundaries. Information that can provide early warning of such accidents or help characterize such events could become critical to peaceful resolution of these severe events. This issue is more than assessing the adversary. Providing transparency of one's own safety status may also avoid misinterpretation by the other side.

Another category of concern is that of security, doctrine, and use control of nuclear forces. There may be a need for adequate information to ensure that weapons are accounted for and secure. This includes the need to know that responsible national entities maintain possession and control over these weapons of mass destruction. It may also include the need to know under what conditions such weapons would be deployed.

In addition to these broad categories of concern over regional nuclear capabilities, future agreements may dictate that specific information is to be provided to demonstrate treaty compliance. Such information might include numbers of weapons, absence of weapons in nondeployment zones, yields or other weapon system capabilities, stocks of materials, training or test activities, and others. As an example, in the Intermediate Range Nuclear Forces (INF) Treaty between the U.S. and Russia, there was a need to declare numbers and basing of treaty-limited items. There was also a need to specify missile dimensions in order to distinguish between treaty-prohibited and treaty-permitted missile production at the Russian missile plant in Votkinsk.

In the absence of agreements requiring information exchange, sharing such information may or may not lead to stability. For example, stating the number of weapons one has in the absence of a weapons limitation agreement could cause an arms race or cause one side to seek advantage over another. Likewise, providing information on weapon storage locations could be used 
to target their destruction in a preemptive strike. It remains a delicate political balance to negotiate the appropriate level of transparency to bring stability without destabilizing the deterrence equation.

\section{Stabilizing Measures and CBMs}

Several stabilizing measures could be undertaken to reduce nuclear concerns that lead to instability. Those discussed here are not exhaustive but represent approaches that could be used to build confidence while addressing issues of concern.

Notifications represent an initial step in transparency. They can be particularly useful in avoiding misinterpretation that can lead to escalation of tension or conflict. Some of these provisions have already been incorporated into security agreements between India and Pakistan. For example, the April 1991 agreement between India and Pakistan on the Advance Notice on Military Exercises, Maneuvers, and Troop Movements specifies notification requirements for land, naval, and air force exercises beyond prescribed levels. The agreement spells out specific timelines and the categories of information that are to be provided. Formalizing similar measures with respect to nuclear concerns could have an equally important impact. Notification of movement or test launch of nuclear capable missiles could avoid misinterpretation and the potential for preemptive military strike. The Lahore Declaration and Memorandum of Understanding in February 1999 recognized the importance of missile launch notification. Since that time, launch notifications have been provided unilaterally in the spirit of Lahore and in the absence of a more formalized agreement. For example, that April the following Indian news item appeared: "But determined to preserve the Lahore momentum, India informed Pakistan and the great powers of the impending Agni test on April 9 two days before the event." 12 Similarly, in Pakistan a Foreign Office statement on the subsequent Ghauri missile test noted, "Pakistan had given prior notification of this test to India in accordance with the Memorandum of Understanding signed in Lahore in February."13

Concerns over misinterpretation of missile launch data are not only theoretical but also historical. During the course of the Cold War there were a number of incidents involving accidents and misinterpretations related to nuclear weapons and delivery systems. Scott Sagan has documented many of these occurrences. ${ }^{14}$ One example of misinterpretation of missile-related data cited by Sagan was the 1979 inadvertent placement of a training tape

12. "Missile Tests and the Lahore Spirit," Hindu, online edition, April 14, 1999.

13. "Pakistan Test-Fires Ghauri-II," News (Pakistan), April 15, 1999.

14. Scott D. Sagan, The Limits of Safety: Organizations, Accidents and Nuclear Weapons (Princeton, N.J.: Princeton University Press, 1993). 
showing a missile attack into the live warning system. Six minutes were needed to assess the threat before determining it was false. While that was sufficient time in the context of U.S./USSR intercontinental missile threats, such time would not be available with the short flight times associated with Indian and Pakistani missile threat. Another incident in 1980, which resulted from a failed computer chip, again led to a false indication of missile attack. Thus, given the small but non-zero likelihood of these or other such incidents, it is essential that India and Pakistan institutionalize the practice and procedures associated with adequate communications, launch notification, and anomaly resolution.

While missile launch notification has implications for immediate crisis stability, other forms of notification may be less urgent but of significance in building confidence and reducing tension. Examples include notification of nuclear material shipments and movements, sharing of atmospheric radiation levels around nuclear facilities, or notification of exercises utilizing nuclear capable forces or equipment.

Declarations may be undertaken unilaterally or as part of formalized agreements. These declarations are often associated with quantities of military equipment. Declaring the number of missiles, missile launchers, nuclear weapons, or nuclear-capable aircraft would be an essential early step in any effort to set arms control limits on these weapon systems. Because of the small and potentially vulnerable nature of the nuclear arsenals of India and Pakistan, it is unlikely that either side would undertake such declarations unilaterally but rather would wait for such time as required under terms of a negotiated treaty. The impact of other nuclear nations in the region, such as China, will also be a factor in any agreement on limits of nuclear capability.

Hotlines offer an opportunity for direct contact between military or government officials in order to defuse tense situations before they escalate to conflict or beyond to employment of nuclear capabilities. In South Asia, hotlines currently exist between the Directors General of Military Operations (DGMOs). They are generally used for communicating about border and other conventional military actions and activities. In the past they have been used for disinformation as well as for intended purposes. ${ }^{15}$ Because of the strategic nature of nuclear weapons, a hotline among heads of state is needed as well to address the most serious issues of conflict including escalation toward nuclear weapon use. While heads of state in India and Pakistan have communicated at past points of conflict, there does not currently exist a dedicated hotline for such purposes. This could be an important tool in managing future crises.

15. Sumit Ganguly and Ted Greenwood, ed., Mending Fences: Confidence and Security Building Measures in South Asia (Boulder, Colo.: Westview Press, 1997). 
Other efforts could be undertaken to reduce the state of readiness of nuclear weapons systems that minimize chances for accidents and require time and deliberate actions to prepare for deployment and potential use. Some of these approaches are thought to characterize the current state of nuclear weapon deployment in India and Pakistan. One such approach is that of demating, which separates the nuclear warhead from the delivery system. By removing the warhead and possibly storing it in a separate location, a time delay is built in that slows the escalation to weapon deployment and use. Additional time delays could be introduced by further disassembling or disabling components of nuclear weapons systems. This disassembly or disablement may be of the warhead itself or other elements of the launch and delivery vehicles.

Another form of de-alerting a nuclear weapon system is to store the weapon and delivery system. Deploying the system would then involve moving it to a launch location. If systems are stored at locations out of range of potential targets, then greater delay is introduced in moving the system to forward deployed locations within range of intended targets. In fact, the establishment of nondeployment zones could be an element of a nuclear stability regime in the region. Maintaining liquid-fueled missiles in an unfueled state also contributes to a de-alerted status. Providing physical barriers or other impediments to launch is another form of maintaining a de-alerted weapon system. These physical barriers, of course, would have to be subjected to periodic checks through agreed-upon methods of surveillance to ensure that they had not been dismantled surreptitiously. Alternatively, these barriers could be suitably armed with tamper-resistant alarms. Attempts to dispense with these alarms would signal the other side that some unauthorized activity was taking place at facilities such as storage or launch sites.

Detargeting seeks to prevent unintentional launch on enemy locations by programming harmless target coordinates into a missile guidance system. In that case, any accidental launch will not result in weapons systems impacting on the territory of an adversary. The U.S. and Russia have detargeted their strategic missile systems as a confidence building measure (CBM). Often broad ocean areas are chosen as default target locations for such missile detargeting.

Concerns over weapon safety and use control are important elements of stability. In the U.S. in the late 1950s a general government nuclear weapon policy was established to assure public safety. In part, it stated "that nuclear weapons and nuclear weapons systems require special consideration because of their political and military importance, their destructive power, and the potential consequences of an accident or unauthorized act. They shall be 
protected against the risk and threats inherent in their environment." 16 The associated safety standards were as follows:

- There will be positive measures to prevent weapons involved in accidents or incidents or jettisoned weapons from producing a nuclear yield;

- There will be positive measures to prevent deliberate arming, launching, firing, or releasing except upon execution of emergency war order or when directed by competent authority;

- There will be positive measures to prevent inadvertent arming launching, firing, or releasing; and

- There will be positive measure to ensure adequate security.

A positive measure was defined as "a design feature, safety device, or procedure that exists solely or principally to provide nuclear safety."17

Incorporation of these concepts in the use of South Asian weapons could reduce the likelihood of accident or weapon use. In the U.S., extensive precautions have been taken to prevent unauthorized nuclear weapon use. According to Stansfield Turner:

In some of our weapons systems, two keys must be turned nearly simultaneously to launch a nuclear weapon, and whenever feasible the keys are physically separated so that one person could not turn both. In others there is an electronic locking system whereby a coded message must be received and inserted into the locking device to unlock it. ${ }^{18}$

While such features as codes and keys may contribute to stability by better controlling access and use of weapon systems, international nonproliferation objectives have prevented any sharing of these capabilities with India or Pakistan. In the interest of reducing the nuclear danger in South Asia, the new U.S. Congress and administration may reconsider specific provisions of this legal impediment.

Imposing limits on nuclear weapon system capabilities and thereby avoiding a full-scale arms race may also be seen as stabilizing measures. These limits may be placed on the numbers, alert status, basing locations (land, sea, and air), or system tests. These limits are the elements from which arms control agreements are derived. However, some progress unilaterally in these areas may build confidence on an informal level that could translate later into formalized agreements. The current self-imposed moratorium on further nu-

16. Stanley D. Spray, "History of U.S. Nuclear Weapon Safety Assessment: The Early Years," SAND96-1099C, Sandia National Laboratories, presented at International Symposium on Science and Society, Moscow, May 1996.

17. Ibid.

18. Stansfield Turner, Caging the Genies: A Workable Solution for Nuclear, Chemical and Biological Weapons (Boulder, Colo.: Westview Press, 1999), p. 68. 
clear testing by India and Pakistan is an example of such constraint even at times of heightened tensions.

\section{Monitoring and Inspection Options in Support of Stabilizing Measures and CBMs}

As India and Pakistan proceed toward full-fledged weaponization, the dangers of crisis stability will increase steadily. Consequently, it is in their interests to pursue political initiatives and adopt certain technological mechanisms to reduce the prospect of crisis instability. While there is value in unilateral stabilizing measures of the types described above, there is often a need to verify such actions in order to have confidence in the notifications or declared actions of an adversary. Such verification demands a reciprocal willingness to reveal information for the benefit of lessening tensions and reducing threats. In addition to providing information needed to address concerns, the cooperative efforts to collect the information can become CBMs.

How can cooperative monitoring play a useful role in reducing these nuclear dangers in South Asia and contribute to crisis stability in the region? Cooperative monitoring involves a variety of technologies and procedures that generate greater transparency and knowledge about the numbers and types of weapons systems and their deployment status. The purpose of such monitoring is to reduce the dangers posed by accidents, inadvertent decisions, and faulty intelligence. To this end, cooperative monitoring techniques can conceivably cover the entire gamut of a country's nuclear weapons infrastructure. In addition to direct monitoring of weapons or missiles, the infrastructure includes but is not limited to production facilities, storage sites, launch sites, and test sites. Monitored activities may include such actions as movements, training, fueling, loading, assembling, or testing of systems or components. Monitoring options include on-site inspections, remotely monitored ground-based sensors, and satellite or aircraft-based remote sensing. These technologies and procedures may be used to verify accuracy of declarations and notifications, assess readiness and deployment status of weapon systems, confirm integrity of weapon security, or evaluate potential weapon system capabilities.

Two caveats are in order. First, all of these technological mechanisms, while increasing transparency, can also have attendant risks. The task before regional decision-makers will be to decide the extent to which these mechanisms can reduce the nuclear danger without compromising national security. Second, none of these mechanisms in and of themselves can contribute to nuclear stability. They will all have to be embedded in political, organizational, and institutional routines, repertoires, and agreements to ensure that they help allay particular fears, concerns, and misgivings. The following ex- 
amples show ways in which monitoring can be used to verify compliance with agreements and lead to greater nuclear stability.

If limits are imposed on the number or type of weapon delivery systems, as was the case in many Cold War nuclear agreements, cooperative monitoring through on-site inspections can be used to verify initial declarations and periodically reconfirm compliance. The use of unique tags to identify controlled items can help ensure that all items are properly inventoried. Inspections are used internationally as an essential element of many nuclear, chemical, and conventional-forces treaties. ${ }^{19}$ Inspections may be bilateral or multilateral. Inspections may also reveal other characteristics, such as the presence or absence of nuclear warheads on missiles using portable radiation sensors. Other features of the alert status of forces such as warhead mating, missile fueling, and launcher readiness can be assessed as part of an inspection regime.

Assessing deployment status could also be enhanced by using remote ground-based monitoring and overhead remote sensing. By monitoring activity levels, for example around key missile facilities, advance notice is provided of events that could be threatening. Such sensor-based monitoring can be continuous. Sensors, such as seismic, magnetic, acoustic, and passive infrared devices, with appropriate telecommunication links can be deployed. Once in place, with proper and periodic maintenance, they can provide timely warning of the movement of missiles within or from a particular facility. These sensors can also be linked to camera or video systems that characterize the nature of the sensor activation by providing photographic images of the events.

To enable monitoring at night, video cameras with thermal imaging capabilities can be added. The installation of video equipment may appear to be even more intrusive. However, because of limited fields of view for video systems, it is possible to limit the surveillance capabilities of these cameras and thereby reduce their intrusiveness relative to other means of monitoring such as inspections. To provide further confidence to anxious adversaries, sites can be monitored with instrumented fences using fiber-optic cables or sensor-activated taut wire systems to provide alarms and warnings about attempts to breach the perimeter of sensitive sites or surreptitiously transfer missiles out of a protected compound. It is important to underscore here that these surveillance capabilities, though seemingly intrusive, have another extremely useful by-product. They can greatly enhance the safety and security of nuclear and ballistic missile capabilities. The existence of these surveillance mechanisms would reduce the danger of unauthorized release or move-

19. For example, the U.S./Russia Intermediate Range Nuclear Forces (INF) Treaty, the Chemical Weapons Convention (CWC), and the Conventional Forces in Europe (CFE) Treaty. 
ment. This concern is especially great in South Asia where insurgent groups may attempt to seize nuclear weapons from their peacetime deployments.

In addition to monitoring storage or deployment locations, such groundbased monitoring systems could be used to assess production activities at weapons plants. For example, the U.S. and Russia have been monitoring missile production at missile plants in both countries under terms of the INF Treaty. Characterizing missile production is achieved through a combination of technical and manual inspection means. While this is not a crisis stability issue, it does relate to longer-term issues of symmetry and strategic balance in the region.

In the South Asian context, such a set of arrangements could help assuage fears about the abrupt movement of missiles in the midst of a crisis, especially since certain missile batteries are believed to be located in states near the borders of India and Pakistan. A possible security objection to the introduction of these sensors needs to be addressed, namely, that the installation of these sensors would alert both sides to the location of key missile emplacements. This objection is dealt with initially by agreeing to limit the deployment of these sensors to well-known facilities. Subsequently, when the political climate so permitted they could gradually expand the number of facilities to be so monitored. Aerial and satellite imagery could be used as tools to reveal deployment of forces over wider areas and may detect clandestine activities not monitored at declared facilities.

Other mechanisms also exist for providing warning of alert status. For example, active seals can be installed on missiles or their erector-launchers. Such a seal might need to be removed to mate a warhead to a missile or to raise the missile launcher into a firing position. By linking these seals with electronic transmission devices, real-time evidence of a change in alert status can be provided to those monitoring an agreement. While such evidence by itself does not constitute a direct threat, it could set into motion the means for resolving the issue before greater escalation of conflict.

Three distinct technological features could also assuage possible concerns about cheating and deception. The presence of multiple sensors would provide a degree of redundancy and thereby reduce the ability to fool or cheat any single device. The sensors could also be equipped with "state of health" mechanisms that would periodically provide information about their continued and reliable functioning. Finally, they could also be configured to provide data authentication. This is a mathematical process of ascertaining that a given signal or set of signals are indeed authentic.

Missile launches provide another source of instability. Missile test flights may be misconstrued as attacks. Therefore, agreeing to notify and jointly monitor missile test flights could avoid possible threat misperceptions. Invited observers and jointly manned radar monitoring could be used to ensure 
that such flights do not pose immediate danger to the other side. In addition to providing prior notification of all missile tests, the two sides could also forswear the testing of missiles along particular trajectories and notify each other of any accidental or unauthorized launches. In order to address this problem, the Memorandum of Understanding (attached to the Lahore Declaration of February 1999) signed by Prime Minister Sharif and Prime Minister Vajpayee calls for the development of mechanisms to prevent unauthorized or accidental use of nuclear weapons.

If there are agreed limits on weapon system capabilities, technology can be used for assessment of some elements of capability. For instance, after the Gulf War in 1991 Iraq was prohibited from possessing missiles with a range in excess of $150 \mathrm{~km}$. Camera systems were installed at missile test stand locations to monitor the size and burn time of missile motors tested there to verify compliance with these limits mandated by the U.N.

Finally, the cooperative deployment of airborne radionuclide monitoring offers a near-term option for nuclear cooperation that can be used to verify safe radiation levels associated with nuclear programs within Indian and $\mathrm{Pa}$ kistan. It has safety and public health implications and, in the early stages of cooperation, may be less controversial than most of the monitoring concepts suggested by this article.

In the prevailing political climate in South Asia, the demands of these intrusive, on-site inspections or sensor deployments seem all but impossible. However, both Indian and Pakistani decision-makers may find it to be in their long-term mutual interest to forge such monitoring regimes. The fashioning of such a regime could reduce the danger of crisis instability by increasing the assurance that the other would not be able to rapidly deploy nuclear forces in the midst of a crisis without being detected.

Not all CBMs lend themselves to monitored solutions. For instance, it is unlikely that detargeting agreements can be verified. The unilateral benefits of reducing risks from accidental or unintended launch may warrant an unverifiable adoption of this policy. Other challenges remain to be addressed as solutions for improved nuclear stability are sought. Providing real-time deployment status without revealing the position of the sensors is one example. Such systems would provide some degree of transparency without the vulnerabilities associated with electronic signals that could be used for targeting items that had transmitting sensors, such as mobile missiles.

The various measures discussed in this paper are not exhaustive, nor do they constitute a technological panacea for resolving the nuclear conundrum in South Asia. However, they constitute a set of possible steps that can be usefully undertaken to reduce the likelihood of a nuclear tragedy in the region as a consequence of human or technological error in a crisis or over periods of long-term tension. 


\section{Constraints and Limitations}

What are the principal constraints and limitations on the forms of cooperation that we have discussed above? A number of factors including political will, state of current affairs, success with initial cooperative efforts, understanding of options, and fear will help determine which activities can go forward. In the end there must be a recognition that cooperation and resolution of conflict are in the best interests of both parties.

At the very outset, most Indian decision-makers would contend that these measures cannot be simply bilateral but must necessarily involve the PRC. There are two responses to this objection. The first response is that while India may well face a significant security threat from the PRC, that relationship lacks the immediacy of the Indo-Pakistani nuclear dyad. India, while it has an ongoing border dispute with the PRC, has managed to stabilize the military situation along that border through a series of confidence and security-building measures. Consequently, there is little reason to believe that a conflict with the PRC is imminent. More to the point, asymmetries in the Indian and Chinese nuclear arsenals greatly reduce the likelihood of any significant nuclear competition in the foreseeable future. The second response is that a set of bilateral measures in the nuclear realm reached with Pakistan may enable India to then start a similar process with the PRC.

In the U.S., decisions must be made on the degree to which dialogue and cooperation with countries in the region on these strategic and crisis management issues is in the long term interests of stability and nonproliferation. Although there is interest in not endorsing or encouraging the nuclear developments in the region, the consequences of ignoring the stability concerns are equally high. Recent reports have indicated a consideration by the Bush administration of renewing higher level military contacts with India. They were suspended as part of the sanctions imposed following the 1998 nuclear tests. This may be a first step leading to a more comprehensive security dialogue.

In India and Pakistan there is a need to resume dialogue and to explore incremental steps in improved relations. Clearly, the prospects of detailed implementation of strategic agreements are still well in the future. However, recent efforts to try to stabilize actions along the LOC may be a first step in expanding areas of security discussion. Domestic political concerns must be addressed and all interested parties must be convinced that peaceful relations and stability are among the most important national security interests of each side.

\section{Building Blocks of Cooperation}

How does one promote cooperation between two long-standing adversaries who assume that they must remain the ultimate guarantors of their own security? The theoretical literature from international relations offers some clues 
about the possible means of promoting cooperation in an anarchic international environment. ${ }^{20}$ One possible strategy is for one of the two adversaries to make a set of unilateral gestures to elicit cooperation from the other. This set of unilateral concessions should engender a degree of trust in the other side and open the pathway to negotiations. Such an outcome may indeed result because both sides see a "shadow of the future," namely the prospect of repeated interactions over time. ${ }^{21}$

Might this strategy have any application to the South Asian context? On the surface, the method has much appeal. Surely India as the major power in the region could well afford to make some unilateral concessions to generate cooperation. Unfortunately, two problems immediately loom. First, it is not clear what exactly constitutes a cooperative act. For example, in December 2000, India offered a cease-fire to the insurgents in Kashmir in an attempt to reduce the level of violence in the state as a precursor to negotiations. A number of the insurgent groups, including the Lashkar-e-Toiba, the Hizb-ulMujahideen (HUM), the Jaish-e-Mohammed, and the Harkat-ul-Mujahideen, refused to abide by the terms of the cease-fire and Pakistan expressed only lukewarm support for it. ${ }^{22}$ Second, states not only look at the "shadow of the future" but also are driven by the "shadow of the past." 23 The long history of tension and conflict between the two states makes leaders extremely wary and suspicious of even seemingly transparent concessions. The Pakistani breaching of the LOC in April-May 1999 after signing the Lahore Declaration in February profoundly reinforced Indian doubts and suspicions about Pakistani motivations. ${ }^{24}$

One possible way out of this conundrum would be for an external power to agree to guarantee the security of one or both parties. Unfortunately, this is not a politically feasible proposition. The only state that could play such a role would be the U.S., as it possesses the requisite material power to effect such an outcome. This prospect, however, is most unlikely. Despite the

20. Robert Jervis, "Cooperation Under the Security Dilemma," World Politics 30:2 (January 1978), pp. 167-214.

21. Robert Axelrod, The Evolution of Cooperation (New York: Basic Books, 1984).

22. Barry Bearak, "Pakistanis and Indians Make Moves for Less Strife," New York Times, December 21, 2000.

23. The authors are indebted to Professor Kanti Bajpai of Jawaharlal Nehru University, New Delhi, for this particular construction.

24. In April 2001, after repeated unilateral extensions of the cease-fire, the Government of India appointed K. C. Pant, the deputy chairman of the Indian Planning Commission, and a respected Indian politician to start negotiations with the insurgents and their supporters. The initial response from the insurgent groups was not favorable. The principal stumbling block appeared to be the unwillingness of the Government of India to involve Pakistan in these negotiations. See B. Muralidhar Reddy, "No Tripartite Talks on Kashmir, Says Nambiar," Hindu, online edition, May 7, 2001. 
U.S.'s concern about the prospects of nuclear war in the region, the particular configuration of the country's political and strategic interests in the subcontinent makes such a U.S. role in the region all but fanciful. More to the point, Indian decision-makers would not welcome such an enlarged U.S. role, given their deep distrust of its motives based upon their reading of the U.S.'s Cold War role in the region. ${ }^{25}$

What, if anything, can be done to ameliorate the prevailing conditions in the region? The U.S. may have to adopt a more calibrated policy toward the region. Such calibration does not mean abandoning its nonproliferation goals. It would, however, entail making available a range of technologies and processes to the two antagonists to enable them to promote nuclear stability in the region and maintain the global nuclear non-use taboo. ${ }^{26}$

Of course, the U.S. would only transfer these technologies to India and Pakistan in the context of the willingness of the two sides to agree to certain political agreements. In effect, the U.S. strategy of providing technologies to stabilize the nuclear relationship would proceed in tandem with the pursuit of various political agreements between India and Pakistan. The onset of such a process could eventually help create organizational constituencies in both India and Pakistan who would see merit to the pursuit of such agreements. One hopes that these constituencies quickly would realize the advantages of having firm control over their nuclear facilities and limiting the prospect of accidental or unauthorized nuclear usage. Building trust through appropriate use of technology while aggressively pursuing diplomatic avenues provides the best hope of forging a stable security relationship between India and Pakistan as they enter the new millennium.

25. For an early and excellent statement of Indian misgivings of the U.S. role in South Asia during the Cold War years, see Baldev Raj Nayar, "Treat India Seriously," Foreign Policy, vol. 18 (Spring 1975), pp. 133-54.

26. Nina Tannenwald, "The Nuclear Taboo," International Organization 43:3 (Summer 1999), pp. 433-68. 